\title{
Utilização dos dispositivos de comunicação da web social pelas bibliotecas universitárias: um espaço para mediação da informação
}

\author{
Use of devices in social web communication \\ through university libraries: A space for \\ mediation of information
}

Raquel do Rosário SANTOS'

Henriette Ferreira GOMES²

\section{Resumo}

A comunicação é fundamental para a interação na construção do conhecimento e mediação da informação. Ao interagir com a biblioteca por meio dos dispositivos de comunicação na Web social, para ter acesso à informação, o sujeito tem a possibilidade não apenas de identificar e localizar informações, mas também de desenvolver, no coletivo, o debate, a troca de informações e realizar outras práticas que auxiliem suas operações mentais em torno dos conteúdos acessados. Dessa maneira, neste artigo, são apresentadas características e possibilidades de utilização dos dispositivos de comunicação da Web social pelas bibliotecas universitárias no desenvolvimento de suas atividades de mediação da informação. Para tanto, foi realizado um estudo bibliográfico, aplicando-se a técnica da análise de conteúdos, com o objetivo de identificar e analisar pesquisas e estudos abordando a temática na Ciência da Informação. Como resultado, foram identificadas diversas modalidades de uso desses dispositivos e suas potencialidades de aplicação no âmbito da biblioteca universitária, concluindo-se que a adoção dos diversos tipos de dispositivos demanda a análise dos objetivos específicos de cada atividade, serviço ou produto que a biblioteca pretenda desenvolver, como também do perfil de seus usuários e da infraestrutura tecnológica disponível. Contudo, numa perspectiva da missão da biblioteca universitária, concluiu-se, ainda, que é latente a necessidade da mesma repensar o seu processo de comunicação e interação com os usuários da informação, buscando utilizar, de maneira mais ampla e eficiente, esses dispositivos de comunicação da Web social.

Palavras-chave: Bibliotecas universitárias. Mediação da informação. Web social.

\begin{abstract}
Communication is imperative for interaction, knowledge construction, and mediation of information. When interacting with the library using communication devices in the social web to obtain access to information, the person has the ability not only to identify and locate information, but also to discuss and exchange of information collectively, and perform and develop practices that enhance mental operations of the content accessed. Thus, this study presents features and possibilities for university libraries to use communication devices in the social web to integrate information activities. Therefore, we applied technique of content analysis to conduct a bibliographic study to identify and analyze surveys and studies on the subject in Information Science. As a result, we identified the different uses of these devices and their potential application within the university library and concluded that the adoption of different types of devices

\footnotetext{
2 Universidade Federal da Bahia, Instituto de Ciência da Informação, Programa de Pós-Graduação em Ciência da Informação. R. Augusto Viana, s/n., Canela, 40110-909, Salvador, BA, Brasil. Correspondência para/Correspondence to: H.F. GOMES. E-mail: <henriettefgomes@gmail.com>.
}

1 Universidade Federal da Paraíba, Programa de Pós-Graduação em Ciência da Informação. João Pessoa, PB, Brasil.

Recebido em 17/10/2012, reapresentado em 17/7/2013 e aceito para publicação em 12/9/2013.
\end{abstract}


requires the analysis of the specific objectives for each activity, service or product that the library wishes to develop, as well as the user profile and the technological infrastructure available. However, in view of the mission of the university library, it was concluded that we need to rethink the process of communication and interaction with users of information in order to use these communication devices in the social web in a broader and more efficient way.

Keywords: University libraries. Mediation of information. Social Web.

\section{Introdução}

Nos últimos anos, as tecnologias de informação e comunicação, mais especificamente os dispositivos de comunicação da Web, vêm fomentando a ampliação de uma cultura participativa, da troca e interlocução de informações entre os sujeitos, provocando mudanças também no modo de comunicação entre bibliotecários e usuários. Nesse contexto, o espaço virtual vem demonstrando ser um importante dispositivo para o processo de disponibilização das informações, um veículo rápido e acessível para o provimento de respostas aos usuários, apresentando-se, assim, como um importante aliado para a construção de redes de conhecimento a partir do ambiente da biblioteca.

A comunicação no espaço virtual tem um papel relevante na dinâmica e crescimento da biblioteca, pois, por meio dessa interação, possíveis barreiras existentes entre ela e o usuário poderão ser reduzidas. Aos usuários, facilita o provimento das suas necessidades de informação, a ampliação do conhecimento e fortalecimento de uma visão crítica. Por outro lado, para a biblioteca, esse tipo de comunicação permite maior agilidade no processo de esclarecimento de dúvidas, orientações, oferta de opções de acesso à informação, permitindo que a biblioteca levante sugestões, receba contribuições, enfim, estabeleça vínculos de parcerias com seus usuários, intensificando um processo de interlocução que favorece a mediação da informação.

Essa perspectiva norteou o desenvolvimento deste estudo que, a partir da adoção do método bibliográfico e da técnica da análise de conteúdo, procurou alcançar o objetivo de identificar e analisar os resultados obtidos em pesquisas e estudos desenvolvidos no campo da Ciência da Informação acerca dessa temática. Os resultados alcançados permitiram a identificação das diversas modalidades de uso dos dispositivos de comunicação da Web social, como também suas potencialidades de aplicação no âmbito da biblioteca universitária, focalizando-se, em especial, as atividades de mediação da informação.

Assim, neste artigo procura-se discutir as características e o uso que a biblioteca universitária pode fazer desses dispositivos, enquanto recursos auxiliares no cumprimento de sua missão de atender as necessidades informacionais, apoiando o processo de apropriação da informação pelos usuários, concluindo-se que é latente a necessidade de se repensar o processo de comunicação e interação da biblioteca com os usuários, utilizando-se, de maneira mais ampla e eficiente, os dispositivos de comunicação da Web social.

\section{Web social e seus dispositivos de comunicação no contexto da biblioteca universitária: a necessidade de adotar novos aliados}

A biblioteca universitária vem desenvolvendo, em seu ambiente físico, uma estrutura que favorece o usuário no acesso, uso e apropriação da informação. Sabendo da grande quantidade de informações que circulam pelos ambientes físicos e virtuais, que muitas vezes não têm um grau de confiabilidade e que demandam tempo do sujeito para a seleção dessa informação, Sousa (2009, p.78, grifo nosso) afirma que:

O papel dos mediadores nunca teve tanta importância como nesses novos tempos em que vivemos, não mais com a carência, mas sim com o excesso de informação disponibilizada na forma impressa, virtual e através dos canais de mídia de massa, cada vez mais modernos.

Nessa perspectiva, destaca-se o papel mediador da biblioteca universitária, que se ocupa de selecionar, organizar e promover a disseminação e circulação da informação, proporcionando maior conforto e segurança aos usuários no desenvolvimento de suas práticas acadêmicas.

Atualmente, os dispositivos de comunicação promovem interferência direta na biblioteca e nas 
atividades de mediação da informação. Peraya (2002, p.29) reflete que:

[...] todos os dispositivos de comunicação midiatizada, todas as mídias, das mais antigas - a escrita, por exemplo - às mais contemporâneas - a Web, a rede Internet, o ciberespaço - constituem dispositivos, mais especificamente dispositivos tecno-semiopragmáticos.

Os dispositivos de comunicação da Web social podem ser importantes aliados da biblioteca na aproximação com os sujeitos, favorecendo tanto a interlocução e cooperação entre eles quanto a circulação, uso e apropriação das informações. Assim, quando utilizados pelas bibliotecas, esses dispositivos podem favorecer as ações mediadoras de informações, tornando mais dinâmica a comunicação entre os usuários que compõem as redes sociais.

A Web social amplia a cultura participativa e dinâmica, possibilitando aos sujeitos uma comunicação mais intensiva e colaborativa nesse espaço. Nesse sentido, Curty (2008, p.55) afirma que a Web 2.0 pode ser compreendida de uma forma mais social, por envolver maior número de pessoas e ser mais participativa, onde "[...] todos são partícipes potenciais e têm condição de se envolver mais densamente; mais apreensível, pois desmistifica que conhecimentos técnicos sejam necessários para a interação [...]".

Ao criar um espaço virtual, utilizando recursos de comunicação da Web social, a biblioteca poderá promover a participação e atuação dos usuários, seja na construção e disponibilização de textos, seja no debate de informações com outros usuários. A "[...] Web 2.0 é um novo espaço para acessar, organizar, gerenciar, tratar e disseminar a informação, conhecimentos e saberes. [...] cabe estudar, experimentar, explorar tecnologias da Web 2.0 para facilitar o acesso e ampliar o uso da informação" (Blattmann \& Silva, 2007, p.211).

No contexto da Web social é necessária a ampliação de informações que desenvolvam o indivíduo cognitivamente, impulsionando-o profissionalmente e academicamente, todavia, esse processo só será efetivado quando os indivíduos utilizarem mais intensamente esse recurso para a construção e disseminação do conhecimento. Desse modo, é imprescindível que a biblioteca universitária atue na construção e ampliação de seus espaços no meio virtual, de forma a possibilitar a formação intensa de redes sociais promotoras do compartilhamento e debate de informações.

Vieira et al. (2008, p.2) refletem que:

[...] a Internet transformou-se, pois, em um espaço democrático de expressão e de acesso à informação nas bibliotecas universitárias, que, através de seus endereços eletrônicos direcionam os usuários para páginas e/ou links, permitindo a interatividade e a participação coletiva [...].

A Web social e seus dispositivos vêm potencializar as atividades realizadas pelas bibliotecas, intensificando a participação do usuário e ampliando a visibilidade dessas atividades. A partir da utilização dos dispositivos de comunicação da Web social, a biblioteca universitária poderá adotar um perfil mais inovador, buscando a colaboração mais ativa dos seus usuários, não mais em uma perspectiva individual, isto é, em que cada usuário contribui isoladamente, sem se identificar e mantendo-se no anonimato; ao contrário, a perspectiva é de uma participação coletiva, com o fomento à troca, debate e produção conjunta de ideias e desenvolvimento de atividades que facilitam o processo de apropriação da informação.

Nesse sentido, existe a necessidade de reflexão acerca das características e possibilidades de utilização dos dispositivos da Web social no ambiente da biblioteca, a fim de ampliar as relações entre os bibliotecários e usuários, como também de promover uma maior disseminação e circulação de informações.

\section{Características e perspectivas de utilização dos dispositivos da web social: uma relação promissora com as bibliotecas universitárias}

No contexto da Web social, dispositivos são desenvolvidos e utilizados para facilitar a interação entre os sujeitos. Os usuários podem apresentar, a partir das discussões em grupos de estudo e pesquisa, ou ainda, em rede social no espaço virtual das bibliotecas, suas necessidades informacionais, como ter acesso a títulos que, por meio de mecanismo de comunicação, poderão ser sugeridos à biblioteca. Ainda por meio dos dispositivos de comunicação, os sujeitos podem eliminar dúvidas, podem sugerir leituras, colaborando para a am- 
pliação do seu conhecimento e do conhecimento de outros sujeitos.

No exame da literatura sobre os dispositivos de comunicação da Web social, percebeu-se a necessidade da construção de um quadro síntese para melhor visualização de suas características, apresentando semelhanças e diferenças entre eles, como também os tipos de conteúdos que podem ser disponibilizados pelas bibliotecas com maior facilidade, visando à mediação da informação. No Quadro 1, pode-se observar que muitos dispositivos podem potencializar a comunicação e a troca de informações no contexto da biblioteca universitária, auxiliando o processo de acesso e uso da informação.

Os dispositivos de Instant Messaging (IM, Mensagens Instantâneas) permitem esclarecer dúvidas no momento em que surgem, por exemplo, dúvidas quanto à disponibilidade de matérias, questões sobre o uso das fontes de informação e sua circulação, além de solicitar informações institucionais como horário de funcionamento, ou ainda esclarecimento sobre atividades que foram ou serão realizadas pela biblioteca, a exemplo de treinamento, palestra ou mesa redonda. A interação por meio desse recurso oferece ao usuário maior conforto, não impondo o deslocamento imediato até o ambiente físico da biblioteca para obter orientação quanto ao uso da biblioteca e das fontes de informação.

Esses dispositivos de comunicação ampliam as atividades que bibliotecários realizam, possibilitando maior aproximação com os usuários, a exemplo daquelas desenvolvidas no serviço de referência, que favorecem a recuperação, o acesso e a utilização das informações com maior rapidez e facilidade.

Conforme afirmam Vieira et al. (2008, p.11, grifo nosso),

[...] o serviço de referência online seria o primeiro serviço beneficiado de forma concreta para possibilitar uma interação e maior motivação para que o usuário se comunique com o bibliotecário para tirar dúvidas. Por outro lado, a biblioteca teria a chance de que o próprio catálogo possa sofrer atualizações baseadas em índices de referências citadas constantemente pelos usuários formando uma espécie de sugestão de compra coletiva.

Esses autores alertam para a importância da utilização desses dispositivos de mensagem instantânea pelas bibliotecas universitárias brasileiras, destacando que o uso desse recurso já é considerado realidade em bibliotecas universitárias americanas. Maness (2007, p.45), também ratifica essa utilização pelas bibliotecas americanas:

Bibliotecas já estão colocando links para seus serviços de referência por chat dentro de seus próprios recursos [...]. Da mesma forma que um usuário em uma biblioteca física está quase por definição perto de um bibliotecário, a referência por chat se tornando mais presente poderia gerar uma circunstância similar no mundo Web.

Essas bibliotecas não estão apenas inovando os seus serviços, mas igualmente se aproximando de seus usuários, estabelecendo uma interlocução mais ativa e promissora.

Os blogs são também dispositivos de comunicação que devem ser explorados no ambiente virtual das bibliotecas. Com a utilização desse dispositivo, os usuários podem compartilhar informações com pares publicando seus textos e reflexões, recebendo contribuições, favorecendo o amadurecimento e a sedimentação das reflexões, além da produção de novos conhecimentos.

Nesse sentido, Curty (2008, p.62, grifo nosso) afirma que, "[...] existem diversos blogs comunitários ou colaborativos, blogs institucionais e temáticos, que buscam discutir assuntos de interesse de determinada comunidade e se articulam de forma semelhante às listas de discussão ou fóruns online". A biblioteca universitária, ao adotar esse dispositivo, poderá ampliar o espaço para discussão e troca de opiniões, tanto de assuntos relacionados ao seu funcionamento, quanto de debates em torno de temáticas que surgiram em sala de aula, grupos de pesquisa e/ou a partir de leituras, possibilitando a formação de redes sociais e a aproximação e interlocução entre os sujeitos.

Constata-se que os usuários se tornam mais participativos quando disponibilizam e trocam informações, interagindo com outros sujeitos. Além de selecionar e sugerir textos que estão no acervo das bibliotecas, os usuários também poderão disponibilizar links para acesso a artigos ou textos na Web que são de interesse comum. Por outro lado, a biblioteca também ressignifica suas atividades com ações ligadas à leitura, saindo dos limites do espaço físico, utilizando e indicando fontes de credi- 
Quadro 1. Principais características dos dispositivos de comunicação da Web social.

\begin{tabular}{|c|c|c|}
\hline \multirow{2}{*}{$\begin{array}{l}\text { Dispositivos de } \\
\text { comunicação da } \\
\text { Web social }\end{array}$} & \multicolumn{2}{|c|}{ Principais funções dos dispositivos } \\
\hline & Semelhanças & Diferenças \\
\hline $\begin{array}{l}\text { Mensagens } \\
\text { Instantâneas (Chat) }\end{array}$ & $\begin{array}{l}\text { Esses dispositivos podem também } \\
\text { ser agregados a dispositivos assín- } \\
\text { cronos, como o facebook e o orkut. }\end{array}$ & $\begin{array}{l}\text { Interação em tempo real entre os su- } \\
\text { jeitos, com visibilidade restrita aos } \\
\text { interlocutores. }\end{array}$ \\
\hline Blog & $\begin{array}{l}\text { Favorece a interação entre os su- } \\
\text { jeitos, fortalecendo e ampliando a } \\
\text { possibilidade de desenvolvimento } \\
\text { de redes sociais. }\end{array}$ & $\begin{array}{l}\text { Possibilita a disponibilização de textos } \\
\text { de grandes dimensões ou reduzidas. }\end{array}$ \\
\hline Twitter & $\begin{array}{l}\text { Possibilita a interlocução entre os } \\
\text { sujeitos, aproximando usuários e } \\
\text { bibliotecários e favorecendo a rela- } \\
\text { ção de sujeitos com afinidades. }\end{array}$ & $\begin{array}{l}\text { Apenas é possível escrever pequenos } \\
\text { textos de até } 140 \text { caracteres. Exige } \\
\text { dos sujeitos a apresentação da infor- } \\
\text { mação de maneira breve e direta, ca- } \\
\text { racterística que pode poupar o tem- } \\
\text { po dos sujeitos no acesso à informa- } \\
\text { ção. }\end{array}$ \\
\hline Wiki & $\begin{array}{l}\text { Permite que os sujeitos se tornem } \\
\text { mais colaborativos, como também } \\
\text { potencializa o trabalho coletivo. }\end{array}$ & $\begin{array}{l}\text { Favorece a produção de textos, ela- } \\
\text { borados coletivamente, possibilitan- } \\
\text { do que qualquer sujeito realize alte- } \\
\text { rações. }\end{array}$ \\
\hline Orkut & $\begin{array}{l}\text { Potencializa a participação dos } \\
\text { usuários e a aproximação deles } \\
\text { com a biblioteca, ampliando as } \\
\text { possibi-lidades de interlocução. }\end{array}$ & $\begin{array}{l}\text { Dispositivo mais direcionado a for- } \\
\text { mação de redes sociais, por disponibi- } \\
\text { lizar recursos como apresentação de } \\
\text { auto-perfil, fotos, vídeos, recados, en- } \\
\text { tre outras informações pessoais. Além } \\
\text { de incentivar os usuários a desenvol- } \\
\text { verem uma lista de sujeitos que têm } \\
\text { maior afinidade, adicionando-os a lis- } \\
\text { ta de contato pessoal. }\end{array}$ \\
\hline
\end{tabular}

Continua

Por meio desse dispositivo os sujeitos interagem entre si e com a biblioteca, favorecendo a aproximação de usuários com características comuns, potencializando a formação de redes sociais.

Flickr

Youtube usuários e deles com a biblioteca.
Dispositivo com as mesmas características do Orkut, direcionado a formação e desenvolvimento de redes sociais.

Favorece a interação entre os Possibilita a disponibilização, organiusuários e deles com a biblioteca. zação e o compartilhamento de imaFavorece a interação entre os gens entre os sujeitos em ambiente virtual. Por meio da apresentação das imagens os usuários inscritos no dispositivo poderão comentar as fotos.

Potencializa a formação e desen- Permite a disponibilização, comparvolvimento de redes sociais, além tilhamento, acesso e comentários a da participação mais ativa dos vídeos na Web. usuários.
Tipo de informação

mais disponibilizada

Por meio desse dispositivo pode ocorrer a troca de qualquer tipo de informação. Dispositivo mais propício para esclarecer dúvidas.

Esse dispositivo pode ser utilizado para divulgar informações sobre a biblioteca, eventos e notícias do campo do conhecimento em que a biblioteca trabalha.

Por meio desse dispositivo a biblioteca pode apresentar links de acesso às informações na Web, como também notícias em geral.

É um dispositivo que mais especificamente pode apresentar informações sobre a biblioteca, suas atividades, equipe, fontes de informações do campo do conhecimento em que está ligada.

A biblioteca pode disponibilizar informações textuais, imagéticas ou multimídias relacionadas ou não com a própria biblioteca, a exemplo, da apresentação de suas atividades de mediação da informação.

Como os dispositivos de comunicação da Web social já apresentados, o facebook também disponibiliza informações tanto da biblioteca quanto de demais instituições, além das informações ligadas ao desenvolvimento da área do conhecimento da biblioteca, mantendo os usuários atualizados.

A biblioteca poderá disponibilizar imagens do seu ambiente físico, dos seus profissionais e das atividades desenvolvidas em seu espaço.

A biblioteca pode criar vídeos que apresentem seu ambiente físico, as fontes de informações ou ainda esclarecendo como se desenvolvem as atividades em seu ambiente. Além disso, podem disponibilizar vídeos e imagens dos eventos que ocorrem em seu espaço, registrandoos e possibilitando que um maior número de usuários possa ter acesso. 
Quadro 1. Principais características dos dispositivos de comunicação da Web social.

\begin{tabular}{|c|c|c|c|}
\hline \multirow{2}{*}{$\begin{array}{l}\text { Dispositivos de } \\
\text { comunicação da } \\
\text { Web social }\end{array}$} & \multicolumn{2}{|c|}{ Principais funções dos dispositivos } & \multirow{2}{*}{$\begin{array}{l}\text { Tipo de informação } \\
\text { mais disponibilizada }\end{array}$} \\
\hline & Semelhanças & Diferenças & \\
\hline $\begin{array}{l}\text { Really Simple } \\
\text { Syndication (RSS) }\end{array}$ & $\begin{array}{l}\text { Favorece a comunicação e intera- } \\
\text { ção entre os sujeitos, como tam- } \\
\text { bém permite que eles possam tro- } \\
\text { car informações. }\end{array}$ & $\begin{array}{l}\text { Permite que os usuários tenham aces- } \\
\text { so às informações divulgadas pela } \\
\text { biblioteca, mantendo-se atualizados } \\
\text { sem a obrigatoriedade de visitarem a } \\
\text { página da biblioteca. }\end{array}$ & $\begin{array}{l}\text { Possibilita que a biblioteca apresente } \\
\text { qualquer informação sobre suas ativi- } \\
\text { dades e eventos, como também outras } \\
\text { informações de interesse dos usuários. }\end{array}$ \\
\hline $\begin{array}{l}\text { Social bookmarking } \\
\text { (delicious) }\end{array}$ & $\begin{array}{l}\text { Esse dispositivo apoia o acesso à } \\
\text { informação de maneira mais rápida } \\
\text { e dinâmica e possibilita que os su- } \\
\text { jeitos possam comentar essas in- } \\
\text { formações, interagindo entre si. }\end{array}$ & $\begin{array}{l}\text { A biblioteca pode organizar e dispo- } \\
\text { nibilizar links de acesso às páginas da } \\
\text { Web, favorecendo a recuperação des- } \\
\text { sas informações pelos usuários. }\end{array}$ & $\begin{array}{l}\text { A biblioteca pode disponibilizar qualquer } \\
\text { informação de interesse dos usuários. }\end{array}$ \\
\hline
\end{tabular}

Fonte: Dados da pesquisa (2012).

bilidade na Web, disponibilizando links de acesso a artigos e textos de revistas científicas, ou ainda ferramentas e recursos gratuitos da Web, interagindo com os usuários de modo mais confortável e motivador.

No que tange às BUFs [Bibliotecas Universitárias Federais] na Web 2.0, os blogs sugerem um melhor relacionamento com os usuários, fortalecendo a imagem da biblioteca, criando fontes de informação, aumentando o tráfego do sítio da biblioteca, quebrando as barreiras de comunicação, incentivando a colaboração e participação em projetos da universidade de forma ativa, gerando novas idéias em conjunto com o bibliotecário e o usuário, e acima de tudo, detendo o poder de persuadir no sentido de mudar a opinião pública. De outra forma a biblioteca é simplesmente vista como um local estático de onde os serviços de referência, que devem ajudar os pesquisadores no desenvolvimento da ciência, ainda merecem maior interatividade (Vieira et al., 2008, p.7, grifo nosso).

Nesse contexto, a biblioteca poderá utilizar o blog para interagir com os usuários, expondo a dinâmica de suas atividades, a exemplo do planejamento e execução da aquisição de fontes, abrindo a possibilidade dos usuários sugerirem novos títulos para o acervo. A biblioteca pode ainda explicar como se elabora referências de livros, CD, artigos, entre outros documentos, que são constantemente utilizados na construção de textos, eliminando dúvidas que sempre surgem na elaboração da lista de referências utilizadas na pesquisa. Assim, a biblioteca pode usar esse dispositivo em auxílio ao usuário, tanto na utilização da informação quanto no desenvolvimento de suas atividades acadêmicas.

Bari (2010, p.12), ao tratar sobre os blogs como um importante dispositivo para interação entre os sujeitos nos ambientes acadêmicos, afirma que:

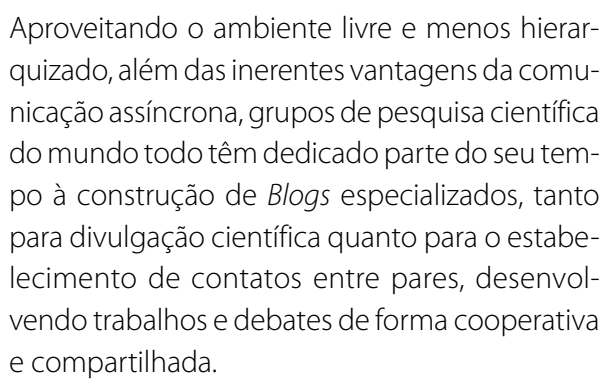

Nesse sentido, os blogs proporcionam aos grupos de estudos e de pesquisas das Instituições de Ensino Superior (IES), um espaço de troca de informações e conhecimentos, favorecendo a comunicação científica e interação entre os sujeitos. Por outro lado, os blogs criados por pesquisadores, grupos de estudos e/ou pesquisas ultrapassam os "muros" das IES, anulando as barreiras do espaço e tempo, auxiliando na disseminação das informações científicas.

A biblioteca pode, por sua natureza cultural, possibilitar o encontro dos usuários com o universo diversificado de informações científicas, objetos culturais, dispositivos tecnológicos e também com outros sujeitos que se interessam pelas mesmas temáticas, estejam eles inseridos ou não na academia. Esse encontro com a heterogeneidade poderá contribuir para a formação 
cognitiva, social e cultural dos sujeitos, incluindo o desenvolvimento de competências informacionais.

\begin{abstract}
Mais uma das implicações da Blogosfera na Universidade é a possibilidade de constituição de ambientes de produção de conhecimento e informação vinculada às funções docentes de discentes, de forma paralela às práticas tradicionais de ensino e pesquisa. O que permite dizer, por exemplo, que a Biblioteca Universitária, por sua centralidade na questão da busca pela informação para cumprimento dos objetivos de ensino e pesquisa, tem a possibilidade de desenvolver a Competência Informacional de grupos sociais heterogêneos, iniciando sua inclusão digital por meio da criação de Blogs unificados ou setoriais, que contam com a participação de bibliotecários, docentes e discentes (Bari, 2010, p.14).
\end{abstract}

Já o twitter permite aos sujeitos o compartilhamento de mensagens resumidas, imagens e indicações de páginas na Web, por meio da disponibilização de links. Nesse dispositivo, a biblioteca pode disponibilizar informações sobre suas atividades, produtos, serviços, horário de atendimento, além de indicar outros dispositivos de comunicação que a biblioteca possui na Web. Dessa maneira, além de ampliar o acesso a informações institucionais e possibilitar aos usuários conhecerem melhor as atividades que desenvolve, a biblioteca poderá também divulgar temas, promover discussões e indicar materiais pertinentes ao campo do conhecimento da biblioteca disponíveis na Web, possibilitando o acesso a informações na Internet que tenham maior grau de confiabilidade.

Por meio desse dispositivo, a biblioteca também pode disponibilizar informações elaboradas por outros sujeitos ou instituições, ação chamada retwittar, disseminando notícias interessantes, conferindo os créditos aos sujeitos que elaboraram a informação.

Resende (2011) indica algumas ações que a biblioteca pode realizar no twitter, como a divulgação de novas aquisições, artigos da área de interesse dos alunos, solicitação quanto a doações para autores/professores, além de manter-se atualizada e identificar quais serviços e produtos os usuários precisam.

Dessa maneira, a biblioteca amplia a aproximação dos usuários com a informação, a exemplo de quando divulga novos títulos adquiridos e disponíveis no acervo ou quando sugere fontes confiáveis e de credibilidade disponíveis para recuperação e acesso na Web. Ela também pode explorar os recursos desse dispositivo para potencializar a formação dos usuários, divulgando treinamentos, oficinas, palestras, seminários, entre outros eventos, realizados por ela ou outras instituições, que contribuirão para o desenvolvimento acadêmico e social dos usuários.

Resende $(2011$, p.6) alerta para o cuidado que se deve ter quanto à maneira de disponibilizar informações no twitter, destacando que "[...] ao colocar a informação sobre um determinado artigo e/ou a divulgação de uma base de dados é importante, mesmo que em 140 caracteres falar o que é aquele link, pois muitos usuários nem abrem o link". Como mediador, o bibliotecário deve estar atento à maneira que desenvolve a disseminação da informação, também nos dispositivos da Web, de modo que possa atrair os usuários para o acesso às informações. O bibliotecário deve desenvolver estratégias convidativas, que atraiam a atenção dos usuários, desenvolvendo o interesse em buscar, acessar e utilizar novas informações.

Por meio da utilização desse dispositivo, a biblioteca pode identificar as necessidades de informação dos usuários, mantendo uma comunicação mais direta com eles. Nesse dispositivo, os usuários têm a possibilidade de fazer sugestões de aquisições para o acervo, bem como de novas atividades ou ressignificação das já existentes. Também podem expor dúvidas e questionamentos, que podem ser respondidos pela biblioteca com agilidade. Conforme defende Resende $(2011$, p.6) esses dispositivos "[...] só possuem razão de existir se as indagações dos usuários forem respondidas [...]. Este tempo de resposta também não pode se estender muito [...]". Além disso, a biblioteca precisa identificar os comentários, dúvidas, questionamentos e sugestões dos usuários, respondendo e também desenvolvendo uma interação que ofereça abertura para uma interlocução continuada.

Outro dispositivo da Web social é o wiki que favorece o exercício de produção de textos, elaborados coletivamente, possibilitando que um número indeterminado de sujeitos possa alterar as informações. Segundo Blattmann e Silva (2007, p.202) "O que distingue o sistema Wiki é que, diferentemente de outras páginas da Internet, o conteúdo pode ser editado e atualizado pelos usuários 
constantemente sem haver a necessidade de autorização do autor da versão anterior". Esse dispositivo, quando utilizado pelas bibliotecas universitárias, pode potencializar atividades de produção de textos voltadas aos usuários, auxiliando-os no desenvolvimento das práticas de escrita.

Esse dispositivo favorece a elaboração de textos coletivos, a troca de informações e a produção de novos conhecimentos, tendo como principal característica a interação entre os sujeitos, favorecendo o desenvolvimento de redes sociais, auxiliando no processo de apropriação da informação. "Por serem ferramentas de colaboração acabam por propiciar um ambiente de compartilhamento e produção de novos conhecimentos promovendo a interatividade, criatividade, diálogo e contribuindo para o processo de aprendizagem cooperada" (Ramalho \&Tsunoda, 2007, p.7).

Se adotado pela biblioteca, esse dispositivo também pode auxiliar no redimensionamento das suas atividades e na participação dos usuários. Como ressaltam Santos e Andrade (2010), por meio do wiki, a biblioteca pode permitir ao usuário "descrever" a outros usuários o que representa para ele, os seus serviços, produtos, acervo, atividades e profissionais. Dessa maneira, os usuários poderão refletir sobre o significado social e cultural da biblioteca.

Por outro lado, por meio do orkut torna-se possível o acesso ao auto-perfil de usuários, scraps (recados), fotos, vídeos, depoimentos e aplicativos. Esses recursos do orkut disponibilizam informações que podem potencializar a interação entre os sujeitos. O perfil, por exemplo, disponibiliza informações pessoais como e-mail, data de aniversário, endereço, escolaridade, entre outras informações. Promove a aproximação entre os participantes que têm afinidades e potencializa a troca de informações entre eles, como a divulgação e o compartilhamento de fotos, vídeos e textos curtos. Também possibilita que um participante tenha acesso a todas as atualizações realizadas pelos contatos.

O Orkut funciona basicamente através de perfis e comunidades. Os perfis são criados pelas pessoas ao se cadastrar, que indicam também quem são seus amigos. As comunidades são criadas pelos indivíduos e podem agregar grupos, funcionando como fóruns, com tópicos (nova pasta de assunto) e mensagens (que ficam dentro da pasta do assunto) (Recuero, 2005, p.5).

Nas comunidades originadas no orkut, os usuários se inscrevem para participar e acompanhar as atualizações do grupo. Essa comunidade se desenvolve por meio de uma temática de interesse do grupo. A partir dela são desenvolvidos debates, enquetes e a interação entre os sujeitos. Assim, tanto na aproximação entre os sujeitos a partir de perfis, quanto nas comunidades, pode existir interação, comunicação e afinidade, gerando um sentimento de pertencimento ao grupo.

A biblioteca pode utilizar o Orkut, tanto desenvolvendo um perfil da biblioteca, quanto criando uma comunidade, de modo que os usuários tenham a possibilidade de interagir e se aproximar de outros com interesses em comum. Dessa maneira, a biblioteca poderá estimular a formação de novas redes sociais.

Refletindo sobre o Orkut, percebemos que seu
sucesso enquanto rede social deve-se ao fato de
que as pessoas encontram nele um canal, um
espaço onde podem expressar gostos, opiniões,
identidades e interesses, manifestando seus
pensamentos e, ao mesmo tempo, sendo ouvi-
dos (lidos) por outros (Bezerra \& Araújo, 2008,
p.208).

Os usuários também poderão utilizar o orkut para "[...] expressar gostos, opiniões, identidades e interesses [...]" (Bezerra \& Araújo, 2008, p.208) e, dessa maneira, serem identificados por pessoas com afinidades semelhantes. Por outro lado, a biblioteca também poderá observar o perfil desses usuários, elaborando estratégias para atraí-los ao uso mais intenso de seus produtos e serviços.

Tanto o orkut quanto o facebook são dispositivos que possibilitam a formação de redes sociais. Os sujeitos podem criar um perfil no qual forneçam seus dados pessoais, profissionais e acadêmicos. A visualização dessas informações pode ser um dos fatores de aproximação entre sujeitos que possuem afinidades, dessa maneira, esses dispositivos potencializam a interação e a comunicação entre os sujeitos.

A biblioteca universitária pode, ainda, utilizar os recursos do facebook, disponibilizando informações da sua área de conhecimento, eventos e notícias importantes, além de disponibilizar links de acesso a textos, artigos, revistas, base de dados e até de outras bibliotecas e instituições importantes para a formação dos usuários. 
Outro recurso que também pode ser utilizado éa disponibilização de fotos e vídeos que poderão auxiliar na apresentação do espaço físico, dos dispositivos e equipamentos que devem ser utilizados pelos usuários. Por meio dos vídeos, pode-se apresentar as atividades realizadas e o papel delas na formação dos usuários. As fotos, especialmente aquelas que expõem o ambiente físico da biblioteca, podem auxiliar na compreensão quanto ao potencial de colaboração da biblioteca para a construção de um ambiente propício ao processo de significação. Os usuários podem reconhecer o ambiente da biblioteca como espaço de estudo, leitura e debate entre os colegas.

Entre os dispositivos da Web social, já apresentados, existem ainda o flickr, youtube, Really Simple Syndication (RSS) e o social bookmarking. O flickr possibilita o compartilhamento de fotos. Segundo Curty (2008, p.59) "[...] o usuário pode descarregar fotos, criar álbuns temáticos e campos descritivos para posterior recuperação, convidar pessoas relacionadas à sua rede de contatos para visualizá-los ou até mesmo deixá-los disponíveis em um grande banco de imagens para acesso coletivo". Esse dispositivo também potencializa a formação de redes sociais, uma vez que os participantes interagem entre si trocando e comentando conteúdos de interesse.

Ao adotar esse dispositivo a biblioteca poderá disponibilizar imagens de seu ambiente, fotos dos seus profissionais, do acervo e eventos que ocorrem em seu espaço. Por exemplo, ao disponibilizar e nomear as fotos da equipe da biblioteca, ela permitirá que os usuários identifiquem as pessoas com as quais eles podem interagir, o que Ihes proporcionará maior conforto na aproximação com a biblioteca. Esse recurso pode ainda aproximar os usuários potenciais, atraindo-os e despertando o interesse por conhecer a biblioteca e participar ativamente de suas atividades.

A biblioteca universitária não deve apenas se preocupar em disponibilizar informações no flickr de maneira estática e mecânica, é importante motivar os usuários a colaborarem e também a realizarem comentários. Por exemplo, a apresentação de fotos do ambiente físico da biblioteca ou de atividades pode fazer com que esses usuários recordem momentos importantes da sua formação ou mesmo de descontração, se sensibilizando quanto à relevância da biblioteca também como ambiente de convivência e fortalecimento das relações sociais. Caso esses usuários comentem ou registrem suas lembranças e experiências nesse ambiente poderão, intencionalmente ou não, contribuir para que outros se sintam motivados a visitar o ambiente físico da biblioteca.

Por sua vez, o youtube potencializa a formação e o desenvolvimento de redes sociais por meio do compartilhamento, indicação e comentários sobre vídeos. Ao selecionar o vídeo desejado, o usuário visualiza no lado direito do dispositivo sugestões de outros vídeos relacionados ao assunto pesquisado. Além disso, o usuário pode interagir com outros apresentando opiniões sobre o vídeo, pois, abaixo deste, ele encontra opções que o ajudam a demonstrar sua apreciação, quais sejam: "gostei"; "adicionar" e "compartilhar". O usuário pode, igualmente, expor comentários publicamente, favorecendo a disseminação da informação, com o desdobramento de possíveis interações com outros sujeitos.

Conforme Curty (2008, p.63) "Esse serviço pode ser considerado líder de vídeos online e a primeira opção para assistir e compartilhar vídeos originais globalmente por meio da Web."A biblioteca pode fazer uso do youtube em paralelo à utilização do flickr, disponibilizando, ainda, vídeos relacionados às suas atividades, treinamentos $\mathrm{e}$ eventos, como também vídeos que aproximem o usuário do ambiente físico da biblioteca, apresentando o acervo e sua equipe.

Como no flickr, a biblioteca não deve apenas se preocupar em disponibilizar os vídeos, é essencial fomentar a participação dos usuários na utilização dos recursos. Ao terem acesso aos vídeos, os usuários podem e devem ser estimulados a realizar comentários, compartilhando suas impressões, o que demonstrará seu grau de satisfação com o acesso à informação. É importante que os usuários interajam com a biblioteca, sugerindo e criticando os conteúdos disponibilizados, de modo que a biblioteca possa avaliar e redimensionar seus serviços.

Já o feeds - Really Simple Syndication (RSS) consiste em um dispositivo que permite a seleção de informações que mais interessam aos sujeitos, de modo que esses possam ter acesso mais fácil e rápido sem precisarem visitar o site de onde a informação foi originada. Segundo Vieira et al. (2008, p.7): 
[...] o programa RSS disponibiliza ao usuário, por meio de uma espécie de 'assinatura', somente o conteúdo selecionado de acordo com a sua necessidade, ou seja, ao invés de visitar os sites para saber as ultimas atualizações, as informações vêm até ele permitindo examinar de forma rápida as novidades dos conteúdos condensados.

Esse dispositivo poderá ser disponibilizado tanto no website da biblioteca quanto em seus dispositivos de comunicação na Web, a partir de um link que possibilita o acesso à página do dispositivo. Também existe a possibilidade da "assinatura" pelos usuários, que podem acompanhar esse feed (dispositivo) pelo "menu"favoritos, na barra de ferramentas do navegador. Dessa maneira, esse dispositivo agrega as informações que mais interessam aos usuários, auxiliando-os no acesso às informações de modo mais confortável.

Além dessas possibilidades vinculadas ao acesso às informações, a biblioteca também pode proporcionar ao usuário a exposição de seus comentários no dispositivo, aspecto que inclui o RSS no conjunto dos dispositivos da Web social já apresentados. A principal característica desse e de outros dispositivos da Web social é a possibilidade de colaboração e exposição de ideias, opiniões e críticas realizadas pelos usuários.

O social bookmarking, ou marcadores sociais, é um dispositivo que permite a organização e recuperação de links possibilitando o acesso às páginas na Web. $O$ usuário cria uma lista com páginas na Web que são de seu interesse, e, de modo confortável, poderá ter acesso a informações, compartilhando-as no momento em que desejar. Assim, esse dispositivo pode favorecer o acesso, a troca e a disseminação de informações na Web pelos sujeitos, além de fomentar o desenvolvimento de redes sociais.

Segundo Santos e Andrade (2010), o delicious pode ser apresentado como um exemplo de sistema que utiliza marcadores sociais. Ao ser adotado pelas bibliotecas, o delicious pode ser utilizado como importante aliado nas atividades desenvolvidas no serviço de referência, por facilitar a disponibilização de informações na Web. A biblioteca poderá utilizá-lo, por exemplo, em apoio a treinamentos, palestras, seminários, entre outros eventos, realizados no ambiente físico ou virtual, disponibilizando e indicando informações na Web para ampliação do conhecimento produzido na atividade. Esse dispositivo também pode favorecer a interação entre os sujeitos na discussão das informações acessadas, o que pode auxiliar a apropriação da informação.

No trabalho"Serviço de referência online: pressuposto para uma biblioteca 2.0", Moraes et al. (2010) relatam o uso de dispositivos da Web social no site do Serviço Técnico de Biblioteca e Documentação (STBD) da Universidade Estadual Paulista (Unesp) do campus de Rio Claro. Entre outros dispositivos, a biblioteca também adotou o delicious, com a criação de um perfil da biblioteca no dispositivo.

Esta ferramenta possibilitou aos bibliotecários adicionar endereços úteis para os usuários da comunidade acadêmica, formando assim um guia de fontes de informação. A atualização desse perfil se dá de forma constante, ou seja, cada vez que o bibliotecário toma conhecimento de uma fonte de informação ou site interessante ela é incluída no perfil (Moraes et al., 2010, p.9).

Essa experiência aponta outro exemplo de uso desse dispositivo, em que a biblioteca também disponibiliza aos usuários informações de credibilidade no ambiente da Web, como os links de acesso a revistas e/ou artigos científicos.

As bibliotecas universitárias precisam considerar a importância desses dispositivos de comunicação para ressignificar e redimensionar suas atividades de mediação da informação, de modo que possam favorecer a interlocução, aproximação e interação entre a biblioteca e o usuário. Como reflete Blattmann e Silva (2007, p.199) "Se antes a Web era estruturada por meio de sites que colocavam todo o conteúdo online, de maneira estática, sem oferecer a possibilidade de interação aos internautas, agora é possível criar uma conexão por meio das comunidades de usuários com interesses em comum, [...]".

A utilização dos dispositivos de comunicação da Web social pela biblioteca universitária proporciona também o fortalecimento das relações entre usuários e entre usuários e bibliotecários. Os usuários são motivados a interagir com o coletivo, trocar, comentar, debater as informações, auxiliando na formação de redes sociais que poderão promover uma nova dinâmica no acesso e uso da informação, favorecendo a apropriação da informação. Por outro lado, a biblioteca no ambiente Web se relaciona mais intensamente com os usuários, e, nessa relação mais direta, passa a apresentar postura mais acolhedora e 
descontraída, facilitando a aproximação com a comunidade acadêmica, favorecendo a aproximação com o público em geral, expandindo o reconhecimento de sua função social na disseminação e acesso à informação científica.

\section{Conclusão}

No contexto da biblioteca universitária, a Web social e seus dispositivos de comunicação tornam-se importantes aliados para o desenvolvimento de novas atividades, como na potencialização daquelas que já são realizadas. É necessário que as bibliotecas utilizem esses dispositivos em toda sua extensão de maneira interativa, permitindo a maior participação dos usuários.

A partir do estudo realizado, foram identificados e analisados dez tipos de dispositivos de comunicação da Web social, verificando-se as diferenças e semelhanças entre eles, e as possibilidades de aplicações nas atividades de mediação da informação realizadas pela biblioteca, buscando-se contribuir para uma adoção mais sistematizada e planejada desses dispositivos. Desse modo, este artigo permite verificar, por meio do exame do agrupamento dos dispositivos apresentado no Quadro 1, que esses se distinguem, principalmente, pelo formato em que as informações são apresentadas. Todos eles têm em comum a possibilidade de uso para a disseminação e promoção do acesso e uso das informações.

Por outro lado, pode-se concluir que, entre eles, o blog, orkut, wiki, facebook, flickr, youtube, feeds-RSS e social bookmarking (delicious), além de permitirem a realização de atividades de disseminação, acesso e uso da informação no ambiente Web, também facilitam uma divulgação mais ampla da própria biblioteca, sua equipe, atividades, produtos e serviços. Já o twitter mostra-se mais adequado à oferta de informações mais breves e concisas, sendo mais apropriado à divulgação de links de acesso à informação na Web, enquanto as mensagens instantâneas (chat) se apresentam como dispositivo mais propício ao processo de troca de informações mais direta entre a biblioteca e o usuário, em especial para o esclarecimento de dúvidas.

Ainda quanto às semelhanças entre os dispositivos, conclui-se que esses sempre estão voltados à promoção da participação e interação entre os sujeitos. Assim, potencialmente, todos podem ser adotados como recurso para o fomento da comunicação com e entre os usuários, por possibilitarem trocas mais dinâmicas de informações, proporcionando maior conforto na interação.

As características analisadas neste artigo sinalizam para a necessidade de se recomendar que a adoção de cada dispositivo seja planejada e efetuada de modo sistematizado, considerando-se as necessidades da biblioteca, do perfil dos usuários e também da infraestrutura tecnológica disponível. Contudo, na perspectiva da missão da biblioteca universitária, compreende-se como principal conclusão a latente necessidade de se repensar o processo de comunicação e interação da biblioteca com os usuários da informação, buscando-se utilizar os dispositivos e comunicação da Web social de maneira mais ampla e eficiente.

\section{Referências}

Bari, V.A. A relação entre a inclusão social na universidade brasileira e o desenvolvimento da competência informacional: implicações no campo teórico da ciência da informação e na prática de seus agentes sociais. In: Encontro Nacional de Pesquisa em Ciência da Informação, 11., 2010, Rio de Janeiro. Anais... Rio de Janeiro: Unirio, 2010. p.1.

Bezerra, M.A.A.; Araújo, E.A. Uma ética da informação para pensar o orkut: reflexões sobre a informação e a liberdade no contexto da sociedade da informação. Informação e Sociedade, v.18, n.2, p.207-218, 2008. Disponível em: <http://www. ies.ufpb.br/ojs2/index.php/ies/article/view/1760/2132>. Acesso em: 12 fev. 2009.
Blattmann, U.; Silva, F.C.C. Colaboração e interação na web 2.0 e biblioteca 2.0. Revista ACB, v.12, n.2, p.191-215, 2007. Disponível em: <http://revista.acbsc.org.br/index.php/racb/ article/view/530/664>. Acesso em: 20 set. 2009.

Curty, R.G. Web 2.0: plataforma para o conhecimento coletivo. In: Tomael, M.I. Fontes de informação na internet. Londrina: Eduel, 2008. p.53-78.

Maness, J.M. Teoria da biblioteca 2.0: web 2.0 e suas implicações para as bibliotecas. Informação \& Sociedade, v.17, n.1, p.43-51, 2007. Disponível em: <http://www.ies.ufpb.br/ ojs2/index.php/ies/article/view/831/1464>. Acesso em: 20 set. 2009. 
Moraes, A.M. et al. Serviço de referência online: pressuposto para uma biblioteca 2.0. In: Seminário Nacional de Bibliotecas, 16., 2010, Rio de Janeiro. Anais eletrônicos... Rio de Janeiro: UFRJ, 2010. Disponível em: <http://www.gapcongressos. com.br/eventos/z0070/trabalhos/final_519.pdf>. Acesso em: 14 mar. 2010.

Peraya, D. O ciberespaço: um dispositivo de comunicação e de formação midiatizada. In: Alava, S. et al. Ciberespaço e formações abertas: rumo a novas práticas educacionais? Porto Alegre: Artmed, 2002. p.25-52.

Ramalho, L.; TsunodaA, D.F. A construção colaborativa do conhecimento a partir do uso de ferramentas wiki. In: Encontro Nacional de Pesquisa em Ciência da Informação, 8. 2007, Salvador. Anais... Salvador: UFBA, 2007. p.1.

Recuero, R.C. Um estudo do capital social gerado a partir de redes sociais no Orkut e nos weblogs. FAMECOS: Mídia, Cultura e Tecnologia, n.28, p.19, 2005. Disponível em: <http://200. 144.189.42/ojs/index.php/famecos/article/viewFile/454/ 381 >. Acesso em: 25 maio 2009.
Resende, E.S. O bibliotecário e a evolução do serviço de referência na biblioteca universitária. In: Congresso Brasileiro de Biblioteconomia, Documentação e Ciência da Informação, 24., 2011, Maceió. Anais... Maceió: Febab, 2011. p.1.

Santos, A.; Andrade, A. Bibliotecas universitárias portuguesas no universo da web 2.0. Encontros Bibli: Revista Eletrônica de Biblioteconomiae Ciência da Informação, n. esp., 2010. Disponível em: <http://www.periodicos.ufsc.br/index.php/eb/article/ view/16586/pdf_23>. Acesso em: 12 jan. 2012.

Sousa, M.M. A biblioteca universitária como ambiente de aprendizagem no ensino superior. 2009. Dissertação (Mestrado em Ciência da Informação) - Escola de Comunicações e Artes, Universidade de São Paulo, São Paulo, 2009.

Vieira, D.V.; Carvalho, E.B.; Lazzarin, F.A. Uma proposta de modelo baseado na web 2.0 para as bibliotecas das universidades federais. In: Encontro Nacional de Pesquisa em Ciência da Informação, 9., 2008, São Paulo. Anais... São Paulo: Enancib, 2008. p.13. Disponível em: <http://www. acquaviva. com.br/enancib2008/cd/>. Acesso em: 20 out. 2009. 